\title{
Jean-Pierre Étienvre, Envites del talante literario en tiempos áureos, Madrid/Kassel, Iberoamericana/Vervuert, 2019, 269 рр. ISBN: 978-84-9192-049-6
}

\section{Victoriano Roncero López}

Stony Brook University

ESTADOS UNIDOS

victoriano.roncero-lopez@stonybrook.edu

[Hipogrifo, (issn: 2328-1308), 9.2, 2021, pp. 1149-1153]

Recibido: 24-06-2021 / Aceptado: 09-07-2021

DOI: http://dx.doi.org/10.13035/H.2021.09.02.81

La prestigiosa editorial Iberoamericana, cuya aportación al estudio de la literatura y cultura áureas es necesario señalar, ha publicado una colección de estudios del hispanista francés Jean-Pierre Étienvre centrados en la concepción de la literatura española como juego, como actividad lúdica en los siglos XVI y XVII, aunque con ramificaciones en la literatura contemporánea. Su producción bibliográfica desde los años 1970 ha incidido en este aspecto de la trascendencia del juego en la literatura, como lo demuestran su temprana edición de Días geniales o lúdricos de Rodrigo Caro (1978) y sus dos libros: Figures du jeu. Études léxico-semantiques sur les jeux de cartes en Espagne (XVIe-XVIII siècle) (1987) y Márgenes literarios del juego. Una poética del naipe. Siglos XVI-XVIII (1990).

La vertiente «naipesca» de su investigación se halla patente en el primer trabajo recogido en el volumen: «Barajas poéticas en la Edad de Oro» (pp. 21-43). Étienvre considera que la poesía es un juego y que el poeta representa al «homo ludens», porque «la norma del verso se yuxtapone a la fantasía de las imágenes, corriendo parejas la métrica con la semántica» (p. 22). A partir de aquí se adentra en los naipes «juego omnipresente» en la España de los siglos XVI y XVII, que aparecen más como motivo que como tema, y establece la presencia de un «lenguaje naipesco» (p. 23). El hispanista francés realiza una serie de calas en el uso del lenguaje de los naipes en distintos tipos literarios, empezando por los juegos «a lo divino», con una clara finalidad moralizante, para seguir con los que aparecen en la poesía cancioneril, entre los que se encuentran los amorosos y los de corte de los Reyes Católicos, como el de Francisco de la Torre y Florencia Pinar, analizados agudamente por Ana Menéndez Collera en su tesis doctoral. Dedica un interesante, aunque dema- 
siado breve espacio, a las «metáforas eróticas» de ciertos términos del juego que presentan un doble significado: bastos, flux, tenderete, atravesar, picar, sota; palabra esta última que se refiere a «mujer deshonesta». Cierra este capítulo una breve cala en las sátiras del tahúr y del fullero, con alusión a los ataques quevedianos a Góngora, en el que concluye cómo el poeta juega con las palabras como el tahúr con los naipes (p. 43).

Los tres trabajos siguientes se centran en la poesía de don Luis de Góngora: los dos primeros tienen las Soledades como objeto de análisis. El primero de ellos, «Los pasos perdidos del peregrino en las Soledades» (pp. 45-53), estudia la figura del protagonista del poema al que define como un joven aristócrata, hermoso, enamorado de una bellísima dama, cuyo desdén provoca su exilio de la corte; el hispanista francés ve a este personaje como un ente pasivo, «protagonista sin protagonismo», con un «caminar inútil para la fábula» (p. 50). El segundo de los trabajos, «Soledad y melancolía. Perfiles de melancolía en las Soledades» (pp. 55-67), sin lugar a dudas el más importante de los recogidos sobre el poeta cordobés, se centra en el tratamiento de estos dos temas en el poema gongorino. Étienvre dedica los primeros párrafos a la soledad gongorina que considera como un afecto, un lugar topográfico y un lugar retórico, al mismo tiempo (p. 57). Pero la mayor parte de este capítulo abunda en la melancolía, identificada con el peregrino protagonista del texto poético. El hispanista francés subraya la aparición del sentimiento en los primeros versos de la Soledad primera y su recurrencia en los primeros de la Segunda, aunque no aparezca la palabra. Góngora convierte el efecto melancólico en un mito poético, de manera que en el poema aparecen muchas figuras de la melancolía. Como parte de esta recurrencia se señala la alusión a los hijos de Saturno, que aparece al principio y al final de Soledades, ya que bajo su signo nacían los melancólicos. Étienvre conecta este afecto con el trauma de la pérdida, recordando que el poema se abre y se cierra con la pérdida, relacionada con la ruina, con la avaricia y con la ambición. Termina el capítulo con dos breves calas sobre los motivos del cisne y del sol negro, y con la definición de la melancolía como ausencia.

El último de los capítulos de este grupo y el más extenso, «Más allá de Mallarmé. El paradigma gongorino en la Francia del siglo XX» (pp. 69-91), tiene que ver con la presencia del poeta cordobés en el mundo poético francés del siglo XX, en el que Góngora es presentado como «paradigma, o referencia variable, pero firme, a lo largo y ancho del siglo XX» (p. 70). Étienvre señala cinco momentos en el devenir de la presencia del autor de Soledades: la publicación de la edición de Foulché-Delbosc de las obras de Góngora (1921); la década de 1920 en la que destaca la publicación en 1920 de un artículo de Jean Casson en L'Esprit Nouveau sobre Góngora y Mallarmé, un artículo de Albert Thibaudet sobre el mismo tema en 1927, o la traducción de veinte sonetos gongorinos por Zdislas Milner en 1928, para terminar en 1932 con la traducción de Lucien-Paul Thomas de los poemas gongorinos con un propósito «pedagógico o vulgarizador», pero de gran importancia, pues «Góngora existía por fin de por sí al norte de los Pirineos» (p. 80); la publicación en 1964 de un libro sobre el poeta cordobés de Pierre Darmangeat; la aparición de traductores 
y eruditos como Michel Deguy y el gran maestro de gongoristas, Robert Jammes; la consideración de Góngora como paradigma del Barroco hecha por Gérard de Cortanze en 1992 en Le Magazine littéraire y la consideración del cordobés como el más grande de los poetas españoles por Sollers en 1992.

Los dos trabajos siguientes tienen como común denominador la figura y obra de Francisco de Quevedo y su relación con lo lúdico. El primero de ellos, «Quevedo ludens: la letra del tahúr» (pp. 93-106), aborda con brevedad el tema del juego en la obra de don Francisco, al que define como «tahúr de vocablos» (p. 93). Es interesante la definición del concepto de lúdico en su estudio sobre Quevedo, pues el hispanista francés afirma que este concepto «no reside solo en el enunciado, ni siquiera en la enunciación, sino que estriba en una concepción global de la ficción literaria» (p. 94). El estudioso francés hace breves calas en algunos aspectos de la poesía quevediana: el erotismo de la baraja en romance, el tema de las tapadas, o las sátiras contra el conde de Villamediana o Góngora. La segunda parte del capítulo aborda la aparición del juego en el Buscón: la descripción de la madre de Pablos, en la que destaca el vocabulario naipesco o el itinerario «tahuresco» del pícaro a lo largo de su autobiografía, para concluir que «el juego, en el Buscón, no es vicio sino lenguaje... es un entretenimiento y lenguaje» (p. 105). En este apartado echamos de menos la referencia de algunos esclarecedores estudios de Ignacio Arellano.

El segundo de los trabajos dedicados a Quevedo lleva por título «En los umbrales de los Sueños: entre provocación y juego» (pp. 107-118). Breves páginas para un tema muy interesante, pues se centra en el análisis de la «perigrafía», es decir, de los textos preliminares. Étienvre señala la importancia que representan esos textos que anteceden al corpus principal de la obra para que el lector pueda comprender en su totalidad lo que leerá a continuación. El hispanista francés centra su análisis en el prólogo a la edición de Juguetes de la niñez que califica como «acto de contrición»» (p. 108) del escritor madrileño, que conmina al lector a que se olvide de la edición de Sueños y dé por definitiva y auténtica la que tiene en sus manos. Creo que aquí el crítico podría haber analizado con más profundidad las diferencias entre ambos textos y sus circunstancias editoriales para dar el valor a esas palabras en las que Quevedo se protege de los lectores de su época que, como Luis Pacheco de Narváez, autor del Tribunal de la justa venganza, esperaban la mínima oportunidad para denunciar sus obscenidades y herejías al tribunal de la Santa Inquisición. Las últimas páginas de este capítulo las dedica el hispanista francés a los prólogos del Discurso de todos los diablos, «dedicatoria grosera, rústica» (p. 111), en los que ataca provocando a los lectores y a los mecenas, y de La culta latiniparla, en la que el escritor se presenta como «iconoclasta hasta en el enmarcamiento de su texto» (p. 118).

El siguiente grupo de artículos se dedica a La Dorotea de Lope de Vega. El primero de estos trabajos lleva como título «Castigo y venganza en La Dorotea» (pp. 119-140), y comienza señalando un detalle importante: la contemporaneidad entre esta «acción en prosa» y la tragedia de El castigo sin venganza. El hispanista francés parte en su estudio del famoso «odi et amo» de Catulo, y concibe la obra 
como la elaboración de la venganza amorosa de Dorotea, aunque al final esta se vea frustrada y quede solamente en deseo y lágrimas. El segundo trabajo sobre la novela de Lope, «Lope 'fiscal de la lengua' en La Dorotea o las dos patrias del Fénix» (pp. 141-157), analiza varias escenas de la obra con una temática literaria, lo que Étienvre define como «metapoesía», y señala cómo las escenas segunda y tercera del acto cuarto construyen el episodio a partir de un soneto burlesco y en torno al comentario del mismo soneto. Todo ello convierte estas dos escenas en una sesión de una justa poética en la que faltan el presidente y el secretario, aunque aparece un fiscal y asistimos a la presentación burlesca de uno de los académicos. El hispanista francés ve en estas páginas una burla de los comentadores y malos imitadores de Góngora, sobre todo de Pellicer, enemistad ampliamente estudiada por Juan Manuel Rozas, aunque acertadamente puntualizada, sobre todo en lo concerniente a las Rimas de Tomé de Burguillos, por Ignacio Arellano. Termina el capítulo con la referencia a la defensa que hace Lope de ciertos poetas que han enriquecido el castellano con un estilo «culto... estilo trabajado y bien claro, a la vez» (p. 151).

«Más acá de la nada. Huecos y vacíos en la escritura barroca» (pp. 159-181). Étienvre resalta el hecho de que la escritura barroca se aprovecha del sincretismo para la invención y lleva al extremo procedimientos heredados de la tradición literaria. Así destaca que para Quevedo y Góngora la nada equivale a la muerte, y que el poeta madrileño medita sobre la muerte, pero al mismo tiempo hace uso de los regodeos verbales; lo que también sucede en el episodio de «La cueva de la Nada» de El Criticón de Gracián. Del jesuita aragonés resalta el hecho de que huecos y vacíos aparecen como conceptos yuxtapuestos. A continuación analiza: la presencia y significado de los huecos en Cervantes, que el escritor alcalaíno señala pero no llena en el autorretrato que aparece en sus Novelas ejemplares; los árboles huecos en Góngora; el hueco como un refugio contra la fealdad del mundo en las Soledades gongorinas; o la equivalencia ignorancia=hueco en Mundo por de dentro quevediano.

Los dos siguientes trabajos constituyen unas breves notas al concepto de lo jocoserio («Primores de lo jocoserio») y el carácter lúdico de la literatura («La literatura como juego (de Gil de Biedma al Lazarillo)»). El primero de ellos es un apunte sobre este concepto, único en las lenguas románicas, pero poco fijado. El estudioso francés aporta textos latinos de Cicerón, Salustio, Tácito y Tito Livio, en los que aparece el término de «joco-seriae». También se menciona el concepto tan caro a los escritores barrocos de las «burlas veras». Señala con posterioridad que para González de Salas lo jocoserio era un estilo y para Quevedo, en los poemas de la musa Talía, era casi un sinónimo de burlesco. El segundo trabajo se presenta como un panorama sobre literatura y juego, partiendo de un poema de Jaime Gil de Biedma: «El juego de hacer versos», juego poético en el que se trata de «imponer a la mente, de manera simultánea, unas realidades o verdades opuestas» (p. 210). Distingue Étienvre entre locus y jocus y separa dos clases de juegos: aquellos en los que predomina la norma, el ejercicio, la repetición aplicada, y aquellos en los 
que predomina la libertad, la fantasía, invención que supera el ejercicio repetitivo, la norma (p. 212). Cierra este breve repaso con la breve alusión a la trampa creada por el anónimo autor del Lazarillo, que ha creado un relato verosímil, haciendo creer al lector que se encuentra ante una autobiografía verdadera.

Cierra el libro una semblanza del añorado Claudio Guillén, «A modo de epílogo Gentleman Claudio (recordando a Claudio Guillén)» (pp. 223-226), en la que el hispanista francés relata algunos de sus encuentros con el maestro y destaca su erudición, su sonrisa, su manera de hablar y su «talante jocoserio» (p. 226).

En conclusión, nos encontramos con un volumen en el que Jean-Pierre Étienvre ha reunido once trabajos y un epílogo con el hilo conductor de la literatura como juego. Quizás hubiéramos deseado una mayor profundización en algunas de las aproximaciones que lleva a cabo a ciertas obras y conceptos, pero el lector puede encontrar en este libro un esclarecedor panorama de un elemento fundamental en la concepción literaria: el juego. 